\title{
Do we remove all the walls? Second Life librarianship
}

\section{Kathryn Greenhill}

More than five hundred librarians have been experimenting with providing library services within Second Life, a Multi User Virtual Environment (MUVE) with over thirty thousand users online at any time. This paper outlines the advantages for librarians of experimenting in Second Life and the technical and managerial decisions librarians should make when considering setting up a library presence in a MUVE. There is an account of the evolution of the Australian Libraries Building within Second Life and a description of some of the scripted library objects created there. The conclusion describes how Second Life librarianship has evolved as librarians become more familiar with the interface.

Manuscript received August 2008. This paper was originally delivered, in a slightly different form, at the VALA 2008 14th Biennial Conference: Libraries / changing spaces, virtual places, 5-7 February 2008, Melbourne. Revised April 2008.

This is a refereed article.

Librarians are experts at managing information within the physical spaces of buildings. We've been doing it for hundreds of years. We have organised information online for more than thirty years, so we are skilled at this. Librarianship in a multi user virtual environment (MUVE) melds these skills in new ways.

\section{The MUVE interface}

MUVEs have been described by Thomas Funkhouser (1995) as:

Multi-user virtual environment applications incorporate computer graphics, sound simulation, and networks to simulate the experience of real-time interaction between multiple users in a shared three-dimensional virtual world. Each user runs an interactive interface program on a "client" computer connected to a wide-area network. The interface program simulates the experience of immersion in a virtual environment by rendering images/sounds/etc. of the environment as 
perceived from the user's simulated viewpoint. Each user is represented in the shared virtual environment by an entity rendered on every other user's computer. Multi-user interaction is supported by matching user actions to entity updates (e.g., motion/sound generation) in the shared virtual environment.

In other words, a MUVE is a game-like online environment accessed by many users simultaneously, where they can interact with other people, objects and their environment within a virtual world.

Second Life owner Linden Lab (http://lindenlab.com/about) describes it as a '3D online digital world imagined and created by its residents' (Second Life 2007a). It is not a game, although it uses an interface similar to PC gaming. Users create three dimensional cartoon representations of themselves called avatars, can carry things in an inventory and interact with their environment. There are, however, no rules, objectives, gameplays, points or levels. The environment is totally designed, built and scripted by the users - who retain copyright in their creations.

Second Life is accessed by client software that users download free from Secondlife.com. The system requirements are broadband access, plus a fast processor and a high-end graphics card (Second Life 2007b). There is no charge for a basic account to use the environment or to create and script objects.

Library experiments in Second Life are laying the foundations for using MUVEs for librarianship. Second Life is not yet a mature, stable system. While I think we should definitely be experimenting and learning the information architecture of Second Life, I do not think we should be trying to serve our client base there. Only 1.48 per cent of Second Life avatars are Australian (Cremorne 2007), which works out to about 5000 people. Only people over 18 years old are allowed to use Second Life under Linden Lab's Terms of Service. In December 2007, the maximum number of users online at the same time showed a very small drop for the first time (Linden 2008). This figure, of around 65,000 concurrent users, is still very large. Compared to sophisticated computer games, the Second Life interface is rather basic. Compared to our flat library web pages, it is an incredibly engaging and immersive way to provide library services online.

Understanding what is possible in Second Life makes it easier to understand how librarians can use a MUVE to experiment with library services. There are three elements: avatars, objects and the environment.

Avatars can interact with other avatars, objects and their environment. By typing into a chat box, avatars can communicate with any avatars within 
20 virtual metres. They can also use Instant Messaging to communicate with any other avatars online at the same time. In August 2007, voice chat became widely available, so users can use headphones and microphones to speak to other avatars. Avatars move through the world by walking, flying and teleporting. They can also be animated to dance, laugh, drive a car or make any other movement.

Objects can be uploaded, built, scripted, sold or animated. You may want to create a teapot, for example, and could do so from basic shapes using the building tools within Second Life. You could also use an external graphics program, like Lightwave 3D, to create the teapot and upload the result. You could add a script to the teapot so that it pours tea when touched, or so that it forces the user's web browser (external to Second Life) to the 'Wonderful World of Teapots' website. You could script it to give the user an object, like a teaspoon or a text-based 'notecard' describing how to make tea. You could use currency, Linden dollars, to purchase teacups, or if another avatar liked your teapot you could give or sell it to them.

Within the environment of Second Life, users can create landscapes and buildings. These landscapes are on islands - virtual parcels of land representing an area of $256 \mathrm{~m} \times 256 \mathrm{~m}$ - each rendered by a single server. An island costs a non-profit organisation like a library around USD840 with USD245 per month maintenance fee (Second Life 2007c).

In some ways, the basic environment of Second Life deliberately replicates real life. It has sky and landscape, plus gravity, light, a setting sun and rising moon, buildings, cities, oceans and a world map. These basic building blocks are used to create places that are very different from the real world.

Multi-media can be streamed into Second Life, so videos of speakers and their presentation slides can be shown on a screen during a real world conference. The environment can interact with third party sites, so users can, for example, draw on an online whiteboard on a website, and have the results shared live in Second Life. There is also a social environment, with searchable groups, profiles and contact lists.

Avatars, objects and the environment interact within a MUVE to create some very interesting prototypes for library services.

\section{The evolution of the Australian Libraries Building in Second Life}

Second Life started in 2003. There were early library services by January 2005. Alliance Library System, a consortium of around 260 libraries in Illinois in the 
United States, started their Second Life Library 2.0 project in April 2006 in a small rented shopfront. By September 2007, this project had grown to over forty affiliated islands in the 'Information Archipelago'. Library activities centre on Info Island, which receives over 6000 visitors a day. The Australian Libraries Building is a two-storey granite building, surrounded by eucalyptus trees, on Cybrary City, one of the islands in the Information Archipelago. It is at coordinates 211, 70, 24.

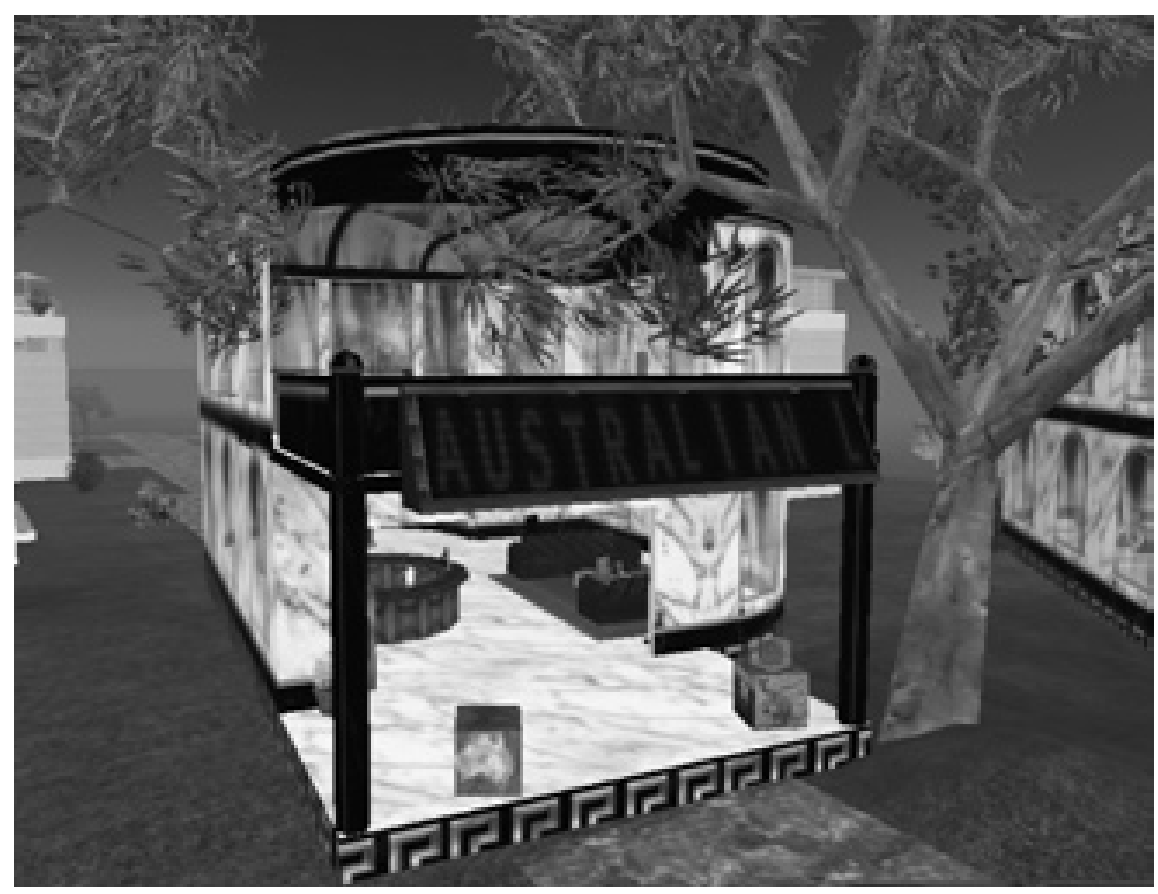

Australian Libraries Building in Second Life, Cybrary City 211, 70, 24

In November 2006, Cybrary City was donated to Alliance Library System (ALS) by Talis, an information management company (Miller 2006). In return for two hours of library volunteer work in Second Life, libraries get a small plot of land and a building free of charge.

After Cybrary City was created, I arranged with Lori Bell from ALS for a guided tour of Second Life libraries as an end of year party for readers and contributors to the Australian library blog, librariesinteract.info (also known as LINT). On November $14^{\text {th }}$, while we were discussing the tour, Lori offered me a building for Australian libraries to use. Too surprised to think about it, I accepted.

I posted about the Australian Libraries Building on LINT, asking whether other Australian librarians wanted to help with it (Greenhill 2006). After two months, we had 14 Australians listed on the 'Australian SL Library Avatars' page of the 
virtual. librariesinteract.info blog (VLINT). A small group met a couple of times in Second Life and set up some basic furniture, including a dance machine, for the end of year party to be held a month later.

Between November 2006 and February 2007, there were five Australian library staff actively using the environment and working on the Australian Libraries Building: Kathryn Greenhill, Constance Wiebrands and Alethea Raspa from Perth, Teresa Bennett from Kalgoorlie and John Chisholm from Alice Springs. As we explored Cybrary City, we met librarians from around the world. Most of them also had buildings in Cybrary City and were new to the environment, so we exchanged plans and showed each other our latest discoveries. The collegial spirit extended to sharing information about our real life libraries.

We learned a lot about using the environment from the librarians of the State Library of Kansas next door. We made a Yellow Brick Road from Kansas library to the 'Oz' library, and were delighted when on the day of the LINT end of year party, the Kansas librarians presented us with a welcome banner, an Australian flag on a flagpole, plus a number of spinning cubes with Australian scenery in the background. Some librarians from the United States were even online in the early hours of their morning so they could attend our party. (CW 2006).

After the LINT end of year party, I added several 'proof of concept' library objects to the Australian Libraries Building, for a live demonstration during a public talk at the National Library of Australia in February 2007. I describe these typical Second Life library objects in the next section.

Since February 2007, the library has been occasionally used as a meeting place and still receives several visitors a week, but it is currently dormant. A project like this requires institutional support to publicise and maintain it. As Tom Peters (2007) observes:

Unfortunately, in Second Life, if you build it, they may not necessarily come. It takes more than an attractive built space to generate usage by avatars. Events, exhibits, organized sets of resources and tools, immersive information and learning experiences, and other interactive activities are needed to energize each built [library] space.

\section{Library Objects within the Australian Libraries Building}

To make the library building interesting for avatars when no-one else was around, I collected or created many objects that show the potential for library service in Second Life. There was no cost for any object except the Australian 
Farmer's Reading Room, which cost around AUD1.50. All objects, except the books, were scripted by me, with help from neighbours in Cybrary City.

Objects inside the Australian Libraries Building include:

\section{Landmark giver}

A floating waist-high cube, with a different Australian scene on each face, rotates slowly in a fixed spot on the front verandah of the building. Hovering above is text saying 'Return to Oz. Touch for a landmark'. When clicked, this adds to the avatar's inventory a link that allows them to teleport back to the building when they want to - a bit like a library contact brochure.

\section{Library buzzer}

A green ball hovers over a similar cube on the other side of the verandah. It indicates when my avatar, Emerald Dumont, is online and allows other avatars to record a short message that is then delivered to me. This can serve a similar purpose to an answering machine or chat reference in a real library.

\section{Libraries Australia bookshelf}

A bookshelf inside the front door has a vase with 'Click to find books in Australian libraries' text hovering above it. When clicked, it directs the users' web browser to the Libraries Australia website.

\section{Bloggy penguins}

Many libraries on Cybrary City replicate a real library by using small PCs on their desks. In Second Life, any object may be used to embed links, so I whimsically placed two penguins on a curved oak counter instead of PCs. When clicked, one goes to the LINT blog and the other goes to the VLINT blog

\section{Door counter}

Just inside the front door is a small object that looks just like a real-life door counter. When its owner types a command into the chat box, it lists the total number and the names of all avatars that have entered the building.

\section{Books}

People who enter the library expect books, so there are two books on a small coffee table. These were obtained from the Caledon Branch Library, 
which replicates a 19th Century English Library. When 'Sense and Sensibility' is clicked, it gives the avatar a text based notecard with an abridged text version of the book, plus a link to a full text electronic version external to Second Life.

The 'Complete works of HP Lovecraft' book is a bit more sophisticated. When users click on it, an open book hovers in the air above the original book. As the user clicks on arrows at the top of the book, a different work is offered. When the desired work is found, the user clicks on the body of the book and is given a notecard containing the complete text. The hovering book can be closed and put back into the original book by clicking on the top right, just like a web page.

\section{Slide viewer}

Toward the back of the library is a clear rectangular panel as tall as an avatar. It contains slide images which can be changed by clicking on forward and back arrows at the bottom of the panel. There are several stereotypical Australian scenes mixed with a couple of slides that I have used in real life presentations about the library.

\section{Library 2.0 monolith}

Dave Pattern from the University of Huddersfield lent us a copy of his 'Library 2.0 Ideas Generator' (Pattern 2006). Avatars click on a large black rectangle and it interacts with a database maintained by Pattern. This randomly combines Library 2.0 buzzwords to produce an idea like 'Podcast your Library Director with comfy chairs and coffee' or 'Gaze lovingly at your library 0.5 colleagues and then turn your library into a funky roller disco'.

\section{Australian Farmer's Reading Room}

Alethea Raspa, a librarian working on the Australian Libraries Building, is a real-life agricultural librarian. Having been told that farmers apparently 'only read when they sit down', she jokingly suggested that a farm dunny linked to some useful library resources might be appropriate.

When I was looking for other Australian-based objects, I found one to fit the bill - complete with rusty corrugated iron. It is now located inside the Australian Libraries Building. A user clicking on it is offered a notecard listing twelve Australian agricultural sites and shown a menu that links to these sites. 


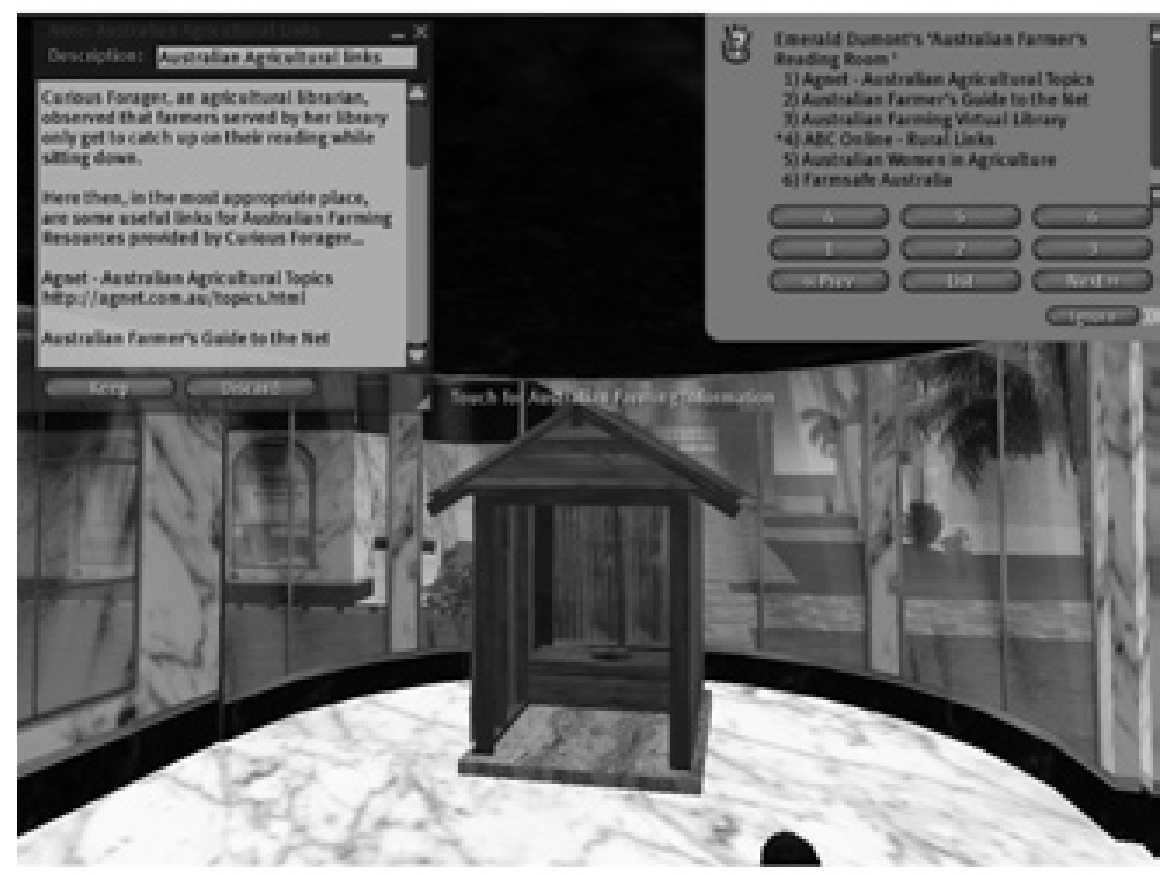

\section{Australian Farmer's Reading room (after user clicks on it)}

\section{Meeting Room upstairs}

The top floor of the library contains a huge Australian flag on the floor, along with a table with one chair, which automatically creates an extra chair every time an avatar sits down. This is designed as a meeting room for any Australians who would like to use it.

Due to lack of staffing, the Australian Libraries Building wasn't able to host events, outreach and classes that are part of some library services on the Information Archipelago, and the objects are not as sophisticated as some of those in other libraries. For an outline of these, see Tom Peter's report into the first year of operation of the Alliance Second Life Library 2.0 project. (Peters 2007).

\section{Advantages of Second Life experimentation for librarians}

There are great professional benefits for librarians who experiment with Second Life. There are limited benefits for our parent organisations and our users - at the moment. The same thing happened when librarians first authored web pages: the first stage was learning how to do it, the second stage was others accessing our output. 


\section{New interface}

Exploring a MUVE is a chance to learn a new web interface. Web browsing in the future won't be identical to Second Life navigation, but it will probably have elements similar to the 3D, social, immersive environment of a MUVE. Learning now how to place objects, create environments, navigate and interact socially within the Second Life environment will make it much easier for librarians to understand future 3D web interfaces.

\section{Understand users who game}

Librarians can learn to relate to PCs as our gaming users do. Although Second Life - without rules, points, objectives and strategies - is not a game, it has many elements of gaming. You control a 3D representation of yourself that has an inventory and interacts with the environment and other people. Gaming can be used for recreation, leisure and, increasingly, to provide information. With PricewaterhouseCoopers estimating that the worldwide video game market will increase from $\$ 31.6$ billion in 2006 to $\$ 48.9$ billion in 2011 (Global Entertainment and Media Outlook: 2007-2011 2007), it is an alternate functional literacy that we should understand.

\section{Fun and creative expression}

Being in Second Life is fun and has great scope for creative expression. Several librarians have remarked to me in Second Life 'I'm having the most fun I've ever had in my professional life'. Librarians can build their ultimate library service. If they don't like something, they can instantly raze and rebuild it. Meetings can happen in exotic locations and librarians can endlessly modify and change their avatars.

\section{Break down professional isolation}

Second Life can help some librarians to combat isolation. Librarians who are geographically isolated, work in one-person libraries or have highly specialised positions can go days without contact with another similar librarian. In Second Life, they can meet other professionals every day.

\section{Increase coding skills}

Creating library services in Second Life is an engaging way to increase coding skills. There are people around to help and example scripts that librarians can modify, but ultimately working on a Second Life library can become a fun challenge that increments librarians' scripting skills, often without being aware of the learning process. 


\section{Become part of a collaborative learning community}

Participating in Second Life allows librarians to join a collaborative learning community. Over 500 librarians are meeting in Second Life, communicating on the Infolsland.org blog and posting to the AllianceSecondLife Google group. Projects such as the Genealogy Library, the Medical Library and Peace Park, which showcases major religions, involve many librarians working across countries and time zones

\section{Network about real-life library topics}

Second Life libraries have programs for librarians to network about general library topics, not just Second Life related projects. There are official programs about topics like MySpace, book discussion groups and author visits. Regular 'Library Buzz' sessions discuss topics like social networking sites, Twitter, Library 3.0, changes to the Medline database and higher education outreach.

\section{Find expert professional support}

In the Information Archipelago, it is easy to meet experts with useful real-life library skills. The reference desk is staffed 80 hours per week, forming a hub where people can meet to exchange ideas. The map navigation in Second Life, which shows other avatars as green dots, makes it easy to find other people on the islands within the Information Archipelago. I have discussed podcasting, single person libraries and library instruction with experts in these fields. One avatar asked me about the scholarly standing of a new Australian law journal, and I was able to do some research and provide an answer.

\section{Free, accessible with a high population}

Second Life is free, we can access it now. It has first mover advantage - the competitive edge gained by being the first in a new market or using a new technology. Second Life interface is primitive compared to current sophisticated gaming interfaces. There are more advanced online virtual worlds. Second Life does have critical mass and is where you'll find the most librarians experimenting.

Tom Peters points out in his report on the first year of operation of the Information Archipelago that, if Second Life were to crash irreparably tomorrow, or some other much better MUVE were to lure away all the residents 
and theoretical knowledge gained during this first collective exploration of virtual worlds would be a sufficiently valuable thing to take away to make the project a worthwhile effort. (Peters 2007)

\section{Flexibility of thought}

The tools of librarianship, like AACR and LCSH, were once standardised, and could be taught in library school. Our toolkit is now rapidly evolving to include blogs, wikis, multimedia and social software tools. These tools themselves are also evolving to become easier to use and able to perform more sophisticated functions. We need people with nimble, exercised minds who are able to adapt to a new environment. There are a hundred different ways to join people with information within Second Life. To successfully create the tools to do this, librarians need to decide what they need to know, work out how they are going to learn it and find the resources available - including other people. The ability to assess and assimilate new tools is a transferable, valuable skill that applies beyond the PC.

\section{Considerations for libraries offering services in Second Life}

Second Life has definite advantages for librarians, but this does not mean that all libraries should set up branches there. Like any potential new service, there are costs, equity issues, and demand from users that should be assessed. There are degrees of library involvement between staff never having heard of a MUVE at one extreme, to managing an island within Second Life on the other.

To develop a change-orientated, nimble workplace able to cope with the current rapid social redefinition of library content and library services, in my opinion, every library should have at least one staff member whose duties include staying aware of new web tools and interfaces like Second Life, and who is able to give input about potential services and new directions for the library. Each library's user base is different, so there needs to be someone on staff able to evaluate new tools and match them to the user base - and to be aware of tools like Second Life which with development may have future use.

It would be extremely useful for this person to have at least created an avatar and experimented with the Second Life interface. Even more useful would be collaboration on one of the library projects within the Information Archipelago like the Science Fiction Portal, the Medical Library on Healthinfo Island or on the reference desk. The learning and networking opportunities would enrich the library to which she belongs. 
Some libraries, like Yarra Plenty in Melbourne and Murdoch University Library where I work, offer training sessions for their communities on creating an avatar. At Murdoch Library, our motivation is to provide exposure and access to Second Life to allow our academic community to assess online virtual worlds as teaching and learning tools.

It is possible to have a Second Life presence without setting up a branch. Parts of buildings or small plots of land are available free or for rent. An Australian library could, for example, use the upstairs meeting space in the Australian Libraries Building or build a display about their library on the lower floor.

Murdoch University Library leased a plot of land on Cybrary City II in March 2007. This is used for workshops open to the university community. Several objects around the plot help workshop participants learn to navigate the Second Life environment: for example, a dance floor, a radio that gave out Murdoch University T-shirts when touched, a starting pack of useful landmarks and objects, a library desk that gave out instructions for the workshop and a set of large granite steps that shows students the 'steps to research'.

Library bodies such as the Library and Archives of Canada, the Michigan Library Consortium and the State Library of Kansas have their own library buildings within Second Life. Michigan and Kansas have used these buildings as meeting places for real life staff in dispersed locations. They also have displays and information about the services their real life libraries offer. Given that part of a state library's function is to promote information about their state, the State Library of Kansas has been particularly successful, with access to maps, statistics and even a life sized tornado in the front yard.

The most time intensive step is owning and managing an entire island. Within the Information Archipelago, this approach has been taken by Stanford University Library, Info Island Denmark, Cleveland Public Library and the San Jose School of Information and Library Studies. San Jose uses the island to teach future librarians. The Danish island is a project of the Danish Library Agency, six municipalities and two other agencies. These are both examples of uses where a larger scale project makes sense.

There are a few considerations when deciding the degree to which (or whether) a library (as opposed to individual librarians) should be involved in Second Life. These are the types of questions I suggest asking:

1. Are my users likely to be in Second Life? Ever?

2. Are my library services ever likely to be delivered using a MUVE interface?

3. Does a significant proportion of my users spend time gaming on their PCs? 
4. Do we have the money, time and staffing to run a virtual branch?

5. Is the brief of my parent organisation to be innovative or experimental or to conduct research?

6. Will there be significant marketing advantages from having a branch in Second Life?

7. Is the library able to offer access to Second Life for users from PCs within our building?

8. Is the library able to offer training for users to access Second Life?

9. Are any services planned in Second Life also available using another medium?

10. Are staff willing to accept that this is both an experimental and a production environment, and to accept that some things may not work, while simultaneously striving to create a professional environment?

\section{Adaptation of library services in an immersive online environment}

Over the last year of experimentation, there have been changes in how librarians work within Second Life. Buildings and services have evolved as librarians have become more skilled in extending the possibilities of the interface. In conclusion, I'm going to outline some changes I have observed within Second Life librarianship.

\section{Evolution of built environment}

I see two conflicting factors influencing the evolution of the built environment for library services in Second Life that require careful balancing. The first factor is the immersive nature of a MUVE. The second factor is the set of features that make an online virtual world different from real life.

The immersive nature of MUVEs is what makes them such an attractive, engaging and effective way of sharing information. The 'willing suspension of disbelief' (Coleridge, cited in Jackson 1985 p.314) - is required for people to feel that their avatar represents them. Representing users as people in a physical world gives a much richer emotional and social experience than representing them as a single headshot in an Instant Messaging interface, even though both are methods of online communication.

The second factor, the set of features that make an online world different from real life, is being further explored as the Second Life libraries mature. People from all over the world can meet, media can be streamed in, avatars can fly and 
teleport. The interface allows combinations of landscapes and objects that would never happen in real life - penguins instead of PCs on a library desk, for example.

Initially, librarians tried to replicate a real-life library environment, complete with Carnegie style library buildings, reference desks, and links to collections represented by books and PCs. This is similar to the way libraries handled the first library OPACs: merely replicating the card catalogue. When we began moving outside this model - offering spelling suggestions and allowing users to rate items - it became a better tool. A similar evolution is happening with Second Life libraries.

In October 2006, when library service began in Second Life, buildings looked like libraries and objects were in roughly the right places. Except - something was wrong. Attempts to replicate real life actually jarred people out of the immersive experience. Stairs, which real life bodies can climb easily, were hard for avatars to navigate when built to real life scale. Corners and walls too close together were hard to navigate without bumping into them. Real-life scale doors were almost impossible to walk through - and most users didn't work out they needed to click on the door to open it anyhow, so just walked past the beautiful buildings with their useful resources.

Users who had discovered that flying was a fast, fun way to navigate the new world were frustrated because it was impossible to enter the building without landing on the ground and walking toward a small door. It was also hard to identify buildings from the air.

Some of the skills learned in the first year of the Second Life Library 2.0 project illustrate this evolution:

... during Year One we quickly learned that reference and welcome centers should be located near teleportation stations. Organizations with buildings in SL quickly learned that having a sign or identifying logo or object located on the roof of the building helps flying avatars spot their destination. (Peters 2007)

When I experimented with removing all the walls in the Australian Libraries Building, it felt like a set of disconnected objects. I immediately put back most of the walls, but kept the front walls off to allow easy access by flying or walking avatars.

In April 2008, the built environment of Info Island looks very different from the original, formal buildings. The reference desk, once a small desk that was extremely difficult for an avatar to sit behind, is now a series of circular platforms. In January 2008, it was redesigned to separate the 'social' and 'informational' functions. It had become a gathering place and a lively social hub, so it became necessary to make a separate space for avatars to ask a 
librarian reference questions. There is still a social space at the reference desk, but it is slightly separate from the space for asking questions.

The Second Life Library 2.0 Building, originally a palatial marble building, is now a series of open-air platforms with holes in the ceiling for avatars to fly through. Instead of being hidden behind walls, collections like 'serials', 'reader's advisory', 'romance' and 'poetry' are clearly visible from most positions near the building.

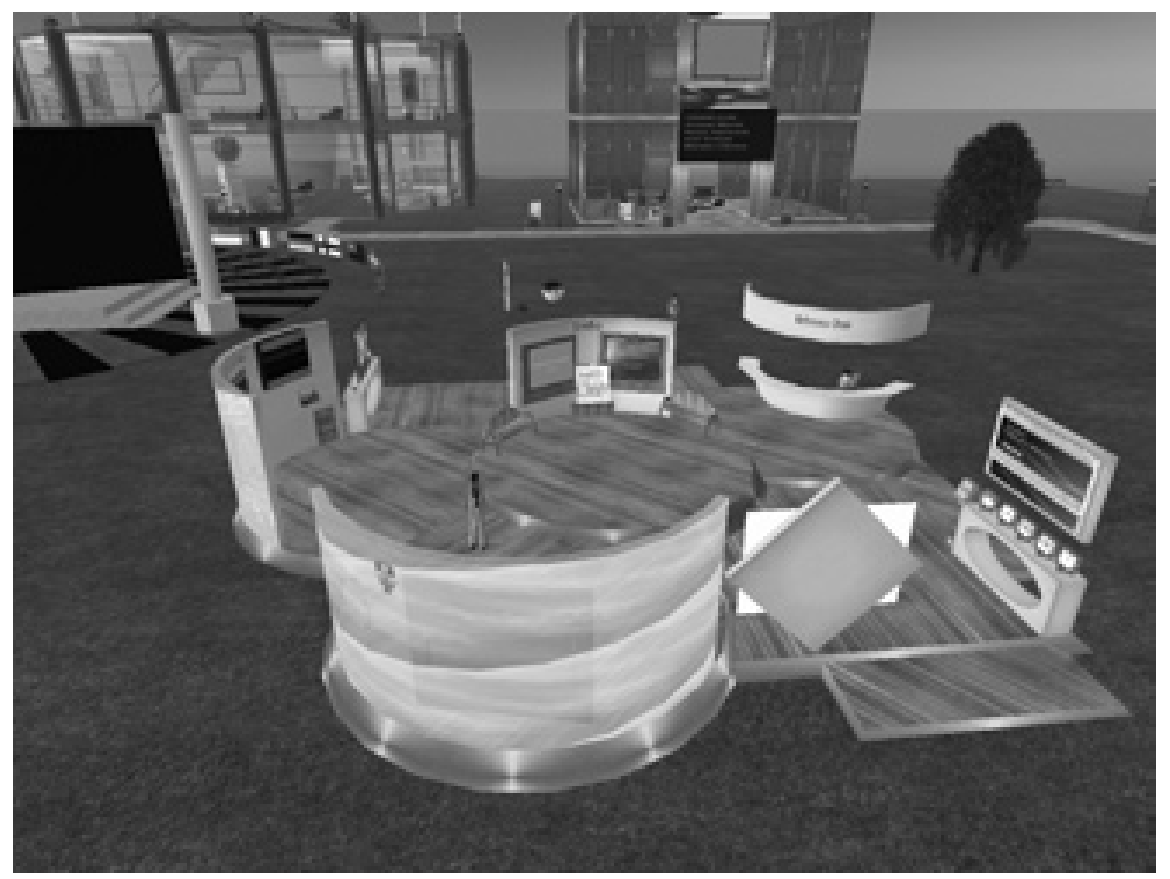

Reference desk on Info Island 1. July 2007.

The Readers' Garden, in the centre of Info Island, designed by avatars Alphonsus Peck and Princess Ivory, is an example of an evolved library that harmonises with the Second Life interface. At the same time, it maintains an immersive environment and the user's willing suspension of disbelief. It bills itself as 'literary events in a non-traditional setting'.

Some features of the Reader's Garden illustrate this balance. Three storeys above the plot is a large cube announcing 'The reader's garden: home of the book discussion circle. Visitors always welcome', intended for flying avatars. The outdoor environment resembles a gazebo in a formal garden with no walls for avatars to walk into. Around a large glass table are seats, but these don't look like chairs; instead, they are large books hovering about knee height. 
In the original design of the Readers' Garden, there was a garden bed with a series of flower bushes in it, next to a wooden control panel that asked: 'Want to talk about a book? Click here to plant a book flower'. Avatars clicking on this could select a flowering bush, which was planted out in the garden bed. They then clicked on it, and were prompted for the title, author and description of the book they'd like to discuss. Subsequent visitors saw the flower and clicked on it to register their interest in discussing the book. The bush owner was emailed each time someone showed interest and then could arrange a discussion time when there were enough people. Unfortunately, the volunteers who designed the garden no longer have time to weed this garden bed.

\section{Evolution of library services offered}

As librarians have experimented with library services in Second Life, the focus has moved from collections of information resources to libraries as a social hub, places to meet and a location for events, exhibitions and training - in a similar way to the metamorphosis of our real life libraries in the last 20 years. This is reflected in the evolution of the Australian Libraries Building. While we worked together to set up the objects, there was a great amount of social interaction and avatars were constantly popping in and out of the building. Once the objects were set up, avatars who had previously been involved drifted off into other pursuits in Second Life or real life. This does not happen to all library projects within Second Life; where there is time and funding to continue projects with events and to develop services, library projects continue to thrive with a social hub of avatars around them.

As Tom Peters observed (2007)

It is entirely possible that libraries in Second Life will be more about exhibits, events, and services than about collections, metadata, and archiving initiatives.

\section{Conclusion}

The game-like interface and capabilities of Multi User Virtual Environments are something that librarians should understand. The Information Archipelago in Second Life, including the Australian Libraries Building, is an excellent starting point for this understanding. The MUVE environment lets us hone our skills and create engaging, immersive environments to display our information. It offers a chance to network with professional colleagues from around the world, and at this experimental stage, to evaluate the benefits and costs of setting up a library branch in a MUVE. 


\section{References}

Cremorne, Lowell 2007, 'Aussie population update - coming up on 5000', The Metaverse Journal 28 March 2007 < http://www.metaversejournal.com/2007/03/28/aussie-populationupdate-coming-up-on-5000/ > [21 April 2008]

CW 2006, 'Great party', 14 December 2006 Available from: < http://virtual.librariesinteract. info/2006/12/14/great-party/ > [17 September 2007]

Funkhouser, Thomas 1995, 'Network services for Multi-User Virtual Environments', paper presented at IEEE Network Realities `95, Boston, October 1995

Global Entertainment and Media Outlook: 2007-2011, PricewaterhouseCoopers, 2007

Greenhill, Kathryn 2006, 'Australian Libraries now have a building in Second Life', librariesinteract.info 14 November 2006 Available from: <http://ibrariesinteract.info/2006/11/14/ australian-libraries-now-have-a-building-in-second-life/ > [17 September 2007]

Infoisland.org: Second Life Library 2.0 (blog for the Alliance Second Life library project) Available from: < http://www.infoisland.org/ > [17 September 2007]

Jackson, HJ (ed.) 1985, Samuel Taylor Coleridge, Oxford, Oxford University Press

librariesinteract.info blog: blog central for Australian Libraries (LINT) Available from: $<$ http://librariesinteract.info $>$ [17 September 2007]

Linden, Zee 2008, 'Second Life economy posts solid growth in Q4', Second Life Blog, 17 January $2008<$ http://blog.secondlife.com/2008/01/17/second-life-economy-postssolid-growth-in-q4/ > [21 April 2008]

Miller, Paul 2006, 'Talis helps bring Cybrary City to Second Life', Panlibus, 8 November 2006. Available from: <http://blogs.talis.com/panlibus/archives/2006/11/talis_helps_bri.php > [17 September 2007]

Pattern, Dave 2006, 'Woot! My first Second Life hack! Self plagiarism is style', 9 December 2006 Available from: <http://www.daveyp.com/blog/index.php/archives/139/ > [17 September 2007]

Peters, Tom 2007, A report on the first year of operation of the Alliance Second Life Library 2.0 Project also known as the Alliance Information Archipelago, April 11, 2006 through April 18 2007, TAP Information Service, Chicago, 10 August 2007

Second Life 2007a, Second Life. Your World. Your Imagination. Available from: $<$ http://secondlife.com> [17 September 2007]

Second Life 2007b, Systems requirements, Available from: <http://secondlife.com/corporate/ sysreqs.php> [17 September 2007]

Second Life 2007c, Land: Islands, Available from: < http://secondlife.com/community/landislands.php> [17 September 2007]

virtual.librariesinteract.info blog: blog central for Australian Libraries in Other Worlds, Available from: < http:// virtual. Librariesinteract.info > [17 September 2007]

Kathryn Greenhill works as an emerging technologies specialist at Murdoch University Library. She can be contacted at: k.greenhill@murdoch.edu.au and her blog can be found at: http://librariansmatter.com 